\title{
Conjunctival Carcinoma pNO TNM Finding v8
}

National Cancer Institute

\section{Source}

National Cancer Institute. Conjunctival Carcinoma pNO TNM Finding v8. NCI Thesaurus. Code C140549.

Conjunctival carcinoma with no regional lymph node metastasis. (from AJCC 8th Ed.) 